AMG tolerability was good. $15-25 \%$ patients had mild dyspepsia. Discontinuation of therapy due to side effects was only in 6 patients $(0.93 \%)$. The development or worsening of arterial hypertension, as well as other cardiovascular complications, was not observed.

Conclusion: AMG is an effective, well-tolerated NSAID, which is appropriate for long-term treatment of OA, RA and AS.

Disclosure of Interests: None declared

DOI: 10.1136/annrheumdis-2019-eular.6102

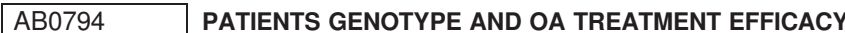

Liudmyla Smolina', 'Liudmyla Khimion", Olexandr Burianov², Nataliia Kicha', Tetiana Sytiuk ${ }^{1}$, Taras Omelchenko ${ }^{2}{ }^{1}$ Shupyk National Medical Academy of Postgraduate Education, Kyiv, Ukraine; ${ }^{2}$ Bogomolets National Medical University, Kyiv, Ukraine

Background: it is known that some genes (FDPS, LCT, VDR) which determine the calcium, vitamin $\mathrm{D}$ and lactate metabolism may have impact on osteoarthritis (OA) development and course, and thus, has a possible influence on $O A$ treatment efficacy.

Objectives: To determine the influence of genetic factors (genotyping of FDPS, LCT, VDR) on the efficacy of standard and modified treatment (with use of the platelet autologous plasma (PAP) in the early stages of knee OA.

Methods: WOMAC index and the frequency of genotype variants for the FDPS, LCT, and VDR genes were studied in 96 patients (57 women, 38 men, $41.7 \pm 1.2$ years old) with primary knee OA (X-ray stage I-II). All patients had $\mathrm{OA}$ exacerbation with no clinical evidence of synovitis. Enrolled patients were divided into 2 groups: the first group consisted of 49 patients (27 women, 22 men, mean age $41.7 \pm 1.2$ years) who agreed to receive standard OA treatment (NSAID, exercises, orthopedic devises - as needed) and 3 intra-articular PAP injections (2 courses in 12 month, plasma volume $12-15 \mathrm{ml} /$ course, total platelet count per injection $\left.1260,24 \pm 22,1 \times 10^{9}\right)$. The second group - 47 patients with OA who received standard treatment. Both groups were comparable by age, gender, body mass index and initial WOMAC. Genetic parameters and its influence on $\mathrm{OA}$ course and treatment efficacy was analyzed during 12 months.

Results: The earliest age $(37.2 \pm 2.01$ years $)$ of clinical manifestation of knee OA was connected to homozygous genotype variants: LCT (relative risk 6.3:1), FDPS (relative risk 6.5:1) and VDR (relative risk 6.8:1). The best positive WOMAC changes was determined in patients with the CC genotype of LCT both in first and second groups. The WOMAC changes showed lower treatment efficacy in patients with CC genotype of FDPS and VDR in both groups, but results of patients who received PAP were better and their remission was longer (in 1.7 times) than in the standard treatment group.

Conclusion: age of knee OA clinical manifestation and the treatment efficacy (both standard and with the use of platelet autologous plasma) has genetic predisposition.

Disclosure of Interests: None declared

DOI: 10.1136/annrheumdis-2019-eular.8401

\section{AB0795 IMPACT OF PRIMARY HAND OSTEOARTHRITIS ON MICROSTRUCTURE AND BIOMECHANICS IN FINGER JOINTS}

David Simon ${ }^{1}$, Koray Tascilar ${ }^{1}$, Sarah Unbehend ${ }^{1}$, Sara Bayat ${ }^{1}$, Timo Meinderink ${ }^{1}$, Andreas Berlin ${ }^{1,2}$, Jürgen Rech ${ }^{1}$, Axel Hueber ${ }^{1,3}$, Georg Schett ${ }^{1},{ }^{1}$ Arnd Kleyer ${ }^{*}$.

${ }^{1}$ Friedrich-Alexander University Erlangen-Nuremberg (FAU) and

Universitätsklinikum Erlangen, Department of Internal Medicine 3, Rheumatology and Immunology, Erlangen, Germany, ${ }^{2}$ Universitätsklinikum Würzburg, Würzburg, Germany, ${ }^{3}$ Klinikum Bamberg, Bamberg, Germany

Background: Primary hand osteoarthritis (HOA) is a heterogeneous disease that is associated with erosive and osteoproliferative changes of the finger joints and progressive functional impairment. Despite these severe changes the effect of HOA on bone mass, microstructure and biomechanics in the affected skeletal regions is largely unknown.

Objectives: To study the effect of HOA on bone microstructure, density and biomechanical properties using high-resolution peripheral quantitative computed tomography (HR-pQCT) of the finger joints and radius.
Methods: HOA patients and healthy controls $(\mathrm{HC})$ underwent HR-pQCT scans of the distal radius and $2^{\text {nd }}$ metacarpal (MCP 2) head. Total, trabecular and cortical volumetric bone mineral densities (vBMD) as well as microstructural and biomechanical properties (failure load) were determined. Failure load and scaled multivariate outcome matrices from dista radius and $2^{\text {nd }}$ metacarpal (MCP 2) head measurements were analyzed using multiple linear regression adjusting for age, sex and functional status and reported as adjusted $\mathrm{z}$ score differences for total and direct effects.

Results: 105 subjects were included $(76 \mathrm{HC} / 29 \mathrm{HOA})$. After adjustment, $\mathrm{HOA}$ was associated with significant changes in the multivariate outcome matrix of the MCP 2 head $(p<0.001)$ explained by an increase in cortical $\operatorname{vBMD}(\Delta z=-1.07, p=0.02)$ and reduction in the trabecular vBMD $(\Delta z=0.7, p=0.09)$ Distal radius analysis did not show an overall effect of HOA however there was a gender-study group interaction explained by reduced trabecular vBMD in males $(\Delta z=1.23, p=0.02)$. HOA was associated with lower failure load [-514 N (95\%Cl:-1025,-2), $\mathrm{p}=0.05]$.

Conclusion: HOA is associated with reduced trabecular and increased cortical bone mineral density and a reduction in radial bone strength Impaired mobility might be an explanation for this reduction. These results underline the clinical importance of HOA-related functional impairment and indicate that HOA patients should be treated with awareness of increased fracture risk and antiosteoporotic treatment.

Disclosure of Interests: David Simon Grant/research support from: Novartis, Consultant for: Lilly, Speakers bureau: Janssen, Koray Tascilar: None declared, Sarah Unbehend: None declared, Sara Bayat: None declared, Timo Meinderink: None declared, Andreas Berlin: None declared, Jürgen Rech Grant/research support from: Bristol-Myers Squibb and Celgene (greater than \$10,000), Consultant for: Bristol-Myers Squibb, Celgene, Chugai, GlaxoSmithKline, Janssen, Eli Lilly, Novartis, Roche, Sanofi Aventis, and UCB (in total more than $\$ 10,000$ ), Speakers bureau: BristolMyers Squibb, Celgene, Chugai, GlaxoSmithKline, Janssen, Eli Lilly, Novartis, Roche, Sanofi Aventis, and UCB (in total more than $\$ 10,000$ ), Axel Hueber Grant/research support from: Novartis, Pfizer, Lilly, Consultant for: Lilly, GSK, Novartis, Janssen, Celgene, Abbvie, Roche, Speakers bureau: Lilly, Janssen, Novartis, Celgene, Biogen, Abbvie, BMS, Georg Schett: None declared, Arnd Kleyer Grant/research support from: Lilly, Consultant for: Lilly, Speakers bureau: Abbvie DOI: 10.1136/annrheumdis-2019-eular.2633

\section{AB0796 DIFFERENCES AND SIMILARITIES OF THE BONE- CARTILAGE UNIT IN PATIENTS WITH PRIMARY OSTEOARTHRITIS AND SECONDARY OSTEOARTHRITIS CAUSED BY RHEUMATOID ARTHRITIS}

${ }^{1,2}$ Rasmus Klose-Jensen ${ }^{*}$, Anne Friesgaard Christensen ${ }^{3}$, Louise

Brøndt Hartlev $v^{1,4}$, Lene Warner Thorup Boel ${ }^{5}$, Mogens Berg Laursen ${ }^{6}$,Kresten Krarup Keller ${ }^{1,7}$, Ellen Margrethe Hauge ${ }^{1,2} .{ }^{1}$ Aarhus University Hospital, Department of Rheumatology, Aarhus, Denmark; ${ }^{2}$ Aarhus University, Department of Clinical Medicine, Aarhus, Denmark, ${ }^{3}$ Lillebaelt Hospital, Department of Internal Medicine, Vejle, Denmark; ${ }^{4}$ Randers Regional Hospital, Department of Clinical Medicine, Randers, Denmark; ${ }^{5}$ Institute of Forensic Medicine, Aarhus University, Aarhus, Denmark; ${ }^{6}$ Aalborg University Hospital, Orthopaedic Surgery Research Unit, Aalborg, Denmark, ${ }^{7}$ Silkeborg Regional Hospital, Department of Clinical Medicine, Silkeborg, Denmark

Background: Despite distinct aetiologies of joint diseases, the osteoarthritic end-stage of primary osteoarthritis and rheumatoid arthritis are described using similar radiological features. However, primary and secondary osteoarthritis may be different at the bone-cartilage unit depending on the pathogenesis.

Objectives: The main purpose was to investigate the histological differen ces in the bone-cartilage unit of the hip joint in patients with primary osteoarthritis and patients with secondary osteoarthritis due to rheumatoid arthritis.

Methods: Femoral heads were obtained during arthroplasty from 12 patients with primary osteoarthritis and six patients with secondary osteoarthritis due to rheumatoid arthritis. Twelve femoral heads from healthy age- and sex-matched subjects were obtained post-mortem. Femoral heads were investigated, using stereological methods to provide unbiased quantitative data. The femoral head, articular cartilage, calcified cartilage, subchondral bone, and osteophytes were measured. 